\title{
The genetic mechanisms of the influence of the light regime on the lifespan of Drosophila melanogaster
}

\section{O. A. Shostal* and A. A. Moskalev}

Radiation Ecology, Center of Ural Division of Russian Academy of Sciences, Institute of Biology of Komi Science, Russia

*Correspondence: olash@list.ru

\section{Edited by:}

Elena G. Pasyukova, Institute of Molecular Genetics of Russian Academy of Sciences, Russia

\section{Reviewed by:}

Elena G. Pasyukova, Institute of Molecular Genetics of Russian Academy of Sciences, Russia

Light is a crucial environmental factor influencing living organisms during their whole lives. It contributes to the regulation of circadian rhythms, affects growth, metabolic rate, locomotor activity and reproduction. The mechanisms of the influence of light on longevity are poorly understood.

We have suggested that there are two relatively independent genetic mechanisms of the influence of light on lifespan (Moskalev and Malysheva, 2010). The first mechanism is related to the damaging effects of light, leading to a reduced lifespan (Figure 1A), the second mechanism is related to the influence of the dark as a mild stressor, which can stimulate the body's defense system and lead to an increased lifespan (Figure 1B).

It is known that an increase in the photoperiod usually decreases the lifespan of experimental animals (Massie and Whitney, 1991; Massie et al., 1993; Sheeba et al., 2000; Majercak, 2002; Anisimov et al., 2004; Vinogradova et al., 2009). An increase in day length promotes a higher level of metabolism due to the intensification of locomotor activity and changes in body temperature of Drosophila (Sheeba et al., 2000, 2002). An increase in metabolic rate, in turn, leads to the additional formation of toxic by-products-free radicals (Massie and Whitney, 1991; Helfand and Rogina, 2003), damaging the cell's mitochondrial and nuclear DNA, membranes and proteins (Le Bourg, 2001), and as a result this can lead to accelerated aging and a reduced lifespan.

In our works (Moskalev et al., 2006, 2008) we investigated the strain Drosophila melanogaster with the defective cytoplasmic superoxide dismutase gene (Sod) which has only $36.7 \%$ of the normal activity of the Cu/Zn Sod enzyme (Phillips et al., 1995) and the strain with the defective mutagen-sensitive 210 gene (mus210), protein-coding, involved in nucleotideexcision repair (homolog of the XPC protein in mammals) (Isaenko et al., 1994). This gene group contributes directly to the elimination of oxidative damagethrough free radical detoxication (gene Sod) and DNA repair (gene mus210). It has been shown that mutations in genes responsible for the removal of oxidative damage can alter the lifespan of animal models. In particular, in Drosophila with zero $\mathrm{Cu} / \mathrm{Zn}$-superoxide dismutase activity, the lifespan is reduced by $80 \%$ (Staveley et al., 1990), and injecting into the short-lived strain Drosophila genome additional superoxide dismutase and catalase genes, basic antiradical protection enzymes, resulted in a lifespan increase (Orr and Sohal, 1994, 2003). Sod overexpression in Drosophila's motor neurons only prolonged the lifespan by $40 \%$ and made Drosophila more resistant to agents stimulating active oxygen formation such as ionizing radiation and paraquat (Mattson et al., 2002). We also know that the ability to repair oxidized DNA bases decreases in XPC-deficient cells (D'Errico et al., 2006). In our experiments, the median lifespan of flies with an impaired Sod gene function also decreased compared with the lifespan of Canton$S$ wild-type flies by $41 \%$ for males and $38 \%$ for females (Moskalev et al., 2006). In the strain with the defective mus 210 gene the median lifespan was reduced by $48 \%$ in males and $21 \%$ females compared with wild-type flies (Moskalev et al., 2006). We hypothesized that in strains with a dysfunction of Sod and mus 210 genes there will be a significant reduction in lifespan if subject to lighting round the clock, as compared to the wild-type strain. According to our results, in strains with Sod and mus210 gene mutations, there was a significant increase in the difference between the median and maximum lifespan in the dark and in the light compared with the Canton-S wild-type strain (Moskalev et al., 2006). In the strain with a free radical detoxication defect, the gap in the median lifespan in the dark and in the light was $36 \%$ for males and $14 \%$ for females; the maximum lifespan was $11 \%$ for males and $24 \%$ for females. At the same time, the addition of the antioxidant melatonin into the food for Drosophila with this defect reduced this variation (Moskalev et al., 2008). In the strain with the DNA repair defect, the gap in the median lifespan in the dark and in the light was $11 \%$ for males and $23 \%$ for females; and the maximum lifespan was $21 \%$ for males and $9 \%$ for females. The lifespan parameters of wild-type flies varied insignificantly (within 0-7\%). Thus, our results confirm our hypothesis about the importance of detoxification and DNA repair genes in the regulation of lifespan under a changing day length (Moskalev et al., 2006, 2008).

It is known that in the regulation of the oxidative stress response and lifespan a key role is played by sirtuin family proteins (Guarente and Kenyon, 2000; Balaban et al., 2005). In response to stress sirtuins deacylate histones and various transcription factors (including p53, FOXO, HSPs), activating the expression of the stress response genes and inactivating and inhibiting apoptosis, thus contributing to the cell survival rate and lifespan increase (Tanno et al., 2007; Niedernhofer and Robbins, 2008). It is known that sirtuins play a key role in the regulation of the aging rate and longevity. In particular, 


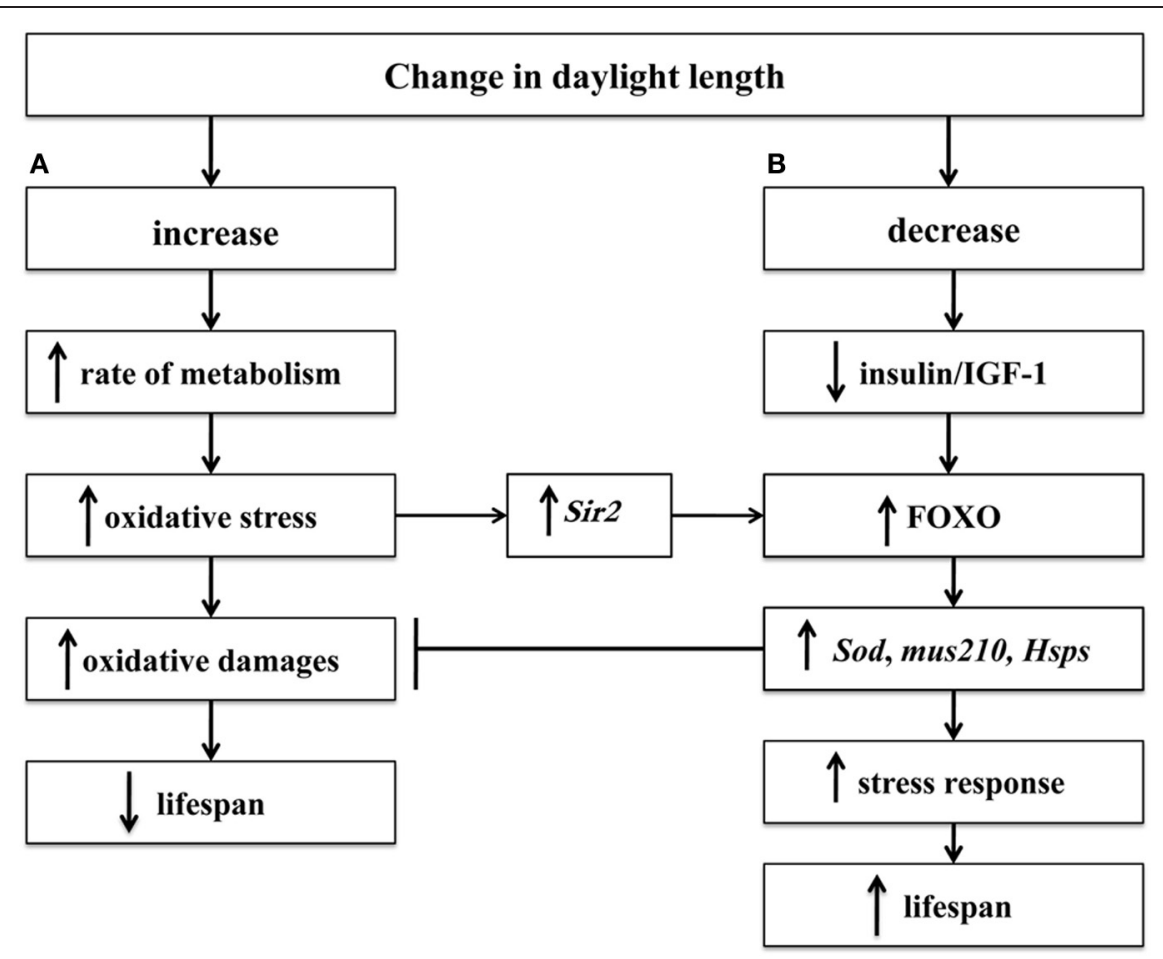

FIGURE 1 | The mechanism of the influence of the light regime on lifespan: metabolism intensification in light conditions (A) and FOXO-dependent increase of lifespan in dark conditions (B). Symbol: $\rightarrow$, induction; $\dashv$, inhibition; $\uparrow$, increase; $\downarrow$, decrease.

the ubiquitous suppression of expression of the dSir2 and two dSir2-like genes (CG5085 и CG6284) by means of RNA interference is lethal, and the suppression of gene expression in Drosophila neurons only reduces the lifespan, while at the same time, increasing the activity of sirtuins in yeast, worms and flies prolongs their lifespan (Kusama et al., 2006; Russell and Kahn, 2007; Niedernhofer and Robbins, 2008). For example, transgenic expression of sir-2.1 prolongs the lifespan of nematodes by $50 \%$, and overexpression of the dsir2 gene in the nerve tissue of Drosophila at the larval stage prolongs the median lifespan of males and females by $20 \%$ and $52 \%$, respectively (Rogina and Helfand, 2004). In our studies dSir2 gene mutation led to a significant reduction in lifespan compared with the wild-type strain. The median lifespan of males and females of the strain with a deletion of the Sir2 gene was lower than the median lifespan of the control strain by $19 \%$ in males and $33 \%$ in females (Moskalev and Malysheva, 2010). The role of sirtuins in the change of lifespan under the influence of different lighting regimes has not previously been studied. We investigated the Drosophila strain homozygous with deletion of the dSir2 gene. It has been shown that the difference in the median lifespan in the dark and light was $24-33 \%$, while in the control wild-type strain the difference in lifespan was $3-17 \%$. Thus, our data point to the important role of the Sir2 gene in the regulation of lifespan under a changing day length (Moskalev and Malysheva, 2010).

Equally important in the cellular stress response are heat shock proteins (Hsps) involved in the process of repair and proteolysis of damaged proteins (Hunt et al., 2004; Arya et al., 2007). Besides, higher Hsps activity is associated with the longer life in various model animals (Morrow et al., 2004; Kimura et al., 2006). The Hsp70 gene expression intensifies after oxidative damage (Guo et al., 2007; Soti and Csermely, 2007), which contributes to the improvement of the redox status of cells and increased activity of antioxidative enzymes (Guo et al., 2007). Moreover, in Drosophila with mutations in genes encoding catalase and $\mathrm{Cu}, \mathrm{Zn}$-Sod, a decrease of the Hsp70 induction period is observed with age, which provides evidence of
Hsp70 involvement in the response to oxidative stress (Landis et al., 2004). We have suggested that the Hsp70 gene deletions in Drosophila can reduce lifespan in light conditions compared to dark conditions (Moskalev and Malysheva, 2010). Notwithstanding the fact that the median lifespan in the light and in the dark of the strains with Hsp70 gene mutations changed slightly, under the exposure to light, the maximum lifespan dropped significantly (by 7-29\%) (Moskalev and Malysheva, 2010).

Thus, the above evidence supports the fact that the lifespan control mechanism in varying daylight conditions is related to the damaging effects of the additional lighting.

Recently, we proposed a hypothesis which suggests that light affects the animal lifespan via neuroendocrine regulatory networks (Moskalev and Malysheva, 2009). According to this hypothesis, in response to the shortening of the photoperiod the activity of the insulin/IGF-1 signaling is decreased, and stress response machinery, including FOXO transcription factor is activated. FOXO plays a crucial 
role in maintaining the balance between growth and reproduction, on the one hand, and stress resistance and lifespan, on the other hand (Calnan and Brunet, 2008). It is known that FOXO mediates the response to oxidative and other stresses, which is often connected with a prolonged lifespan (Giannakou and Partridge, 2004; Vogt et al., 2005; Lam et al., 2006; Honda et al., 2010). It was shown that permanent overexpression of $d F O X O$ in the fat body of an adult Drosophila reduces the mortality rate, stimulates the resistance to the free radical inducing factor-paraquat and prolongs the lifespan of flies (Giannakou and Partridge, 2004; Giannakou et al., 2007), whereas any defects in the functioning of $d F O X O$ raises sensitivity to oxidative stress and decreases the lifespan (Junger et al., 2003). We have suggested that FOXO plays the key role in the increased lifespan when in the dark. In this case, the experimental reduction in the activity of this gene should eliminate the difference between the lifespan in the dark and in the light. Flies with reduced $d F O X O$ gene function were obtained by mating flies of two strains containing the $d F O X O^{21}$ and $d F O X O^{25}$ alleles. In $d F O X O^{21} / d F O X O^{25}$ transheterozygotes the survival curves in the dark and under normal lighting conditions did not differ significantly in three out of four cases (Moskalev and Malysheva, 2010). This result points to the connection between the longevity of fruit flies in the dark and the activity of the FOXO transcription factor. Apparently, the minimum differences in survival of flies with reduced FOXO function in the dark and under normal lighting conditions remained because the induction of FOXO-dependent stress resistance mechanisms can occur not only in response to the suppression of insulin-like peptides in the dark, but also in response to oxidative stress in the light, adding to the reduction in lifespan in the light (Moskalev and Malysheva, 2010).

Thus, we obtained the first evidence of the role of FOXO transcription factor in the control of lifespan in varying light regimes. This role is expected to be determined by its involvement in the response to the mild stress effect of darkness.

Overall, the results of our research substantiate our hypothesis regarding the existence of two relatively independent regulatory pathways that respond to changes in lighting regimes (Figure 1). On the one hand, the increased photoperiod resulting in the intensified metabolism leads to the decreased lifespan of Drosophila. Actually, the strains with Sod, mus210, and dSir2 gene mutations demonstrate a significantly higher difference in the lifespan in the dark and in the light with regard to the wild-type strains, and for the strains with mutations in $H s p 70$ gene such regularity is a trend. On the other hand, the decreased photoperiod, although it does not cause damage, stimulates the stress response and prolongs the lifespan. In the case of reduced activity of FOXO transcription factor the increase in the Drosophila lifespan in the dark is poorly pronounced or absent, which substantiates our hypothesis that Drosophila have a FOXO-dependent mechanism of increasing lifespan in the dark (Moskalev and Malysheva, 2010).

The authors were supported by the grant from the Presidium of the Russian Academy of Science No. 12-P-4-1005; and grants from the Russian Foundation for Basic Research No. 12-04-31922 and 12-04-32261.

\section{REFERENCES}

Anisimov, V. N., Baturin, D. A., Popovich, I. G. Zabezhinski, M. A., Manton, K. G., Semenchenko, A. V., et al. (2004). Effect of exposure to lightat-night on life span and spontaneous carcinogenesis in female CBA mice. Int. J. Cancer 111, 475-479.

Arya, R., Mallik, M., and Lakhotia, S. C. (2007). Heat shock genes - integrating cell survival and death. J. Biosci. 32, 595-610.

Balaban, R. S., Nemoto, S., and Finkel, T. (2005) Mitochondria, oxidants and aging. Cell 120, 483-495.

Calnan, D. R., and Brunet, A. (2008). The FoxO code. Oncogene 27, 2276-2288.

D’Errico, M., Parlanti, E., Teson, M., De Jesus, B. M., Degan, P., Calcagnile, A., et al. (2006). New functions of XPC in the protection of human skin cells from oxidative damage. EMBO J. 25, 4305-4315.

Giannakou, M. E., Goss, M., Jacobson, J., Vinti, J., Leevers, S., and Partridge, L. T. (2007). Dinamics of the action of dFOXO on adult mortality in Drosophila. Aging Cell 6, 429-438.

Giannakou, M. E., and Partridge, L. (2004). The interaction between FOXO and SIRT1: tipping the balance towards survival. Trends Cell Biol. 8, 408-412.

Guarente, L., and Kenyon, C. (2000). Genetic pathways that regulate ageing in model organisms. Nature 409, 255-262.

Guo, S., Wharton, W., Moseley, P., and Shi, H. (2007). Heat shock protein 70 regulates cellular redox status by modulating glutathione-related enzyme activities. Cell Stress Chaperones 12, 245-254.
Helfand, S. L., and Rogina, B. (2003). Genetics of aging in the fruit fly Drosophila melanogaster. Annu. Rev. Genet. 37, 329-348.

Honda, Y., Tanaka, M., and Honda, S. (2010). Redox regulation, gene expression and longevity. Geriatr. Gerontol. Int. 10, 559-569.

Hunt, C. R., Dix, D. J., Sharma, G. G., Pandita, R. K., Gupta, A., Funk, M., et al. (2004). Genomic instability and enhanced radiosensitivity in Hsp70.1and Hsp70.3-deficient mice. Mol. Cell. Biol. 24, 899-911.

Isaenko, O. A., Romashkina, T. B., Shvartsman, P. Y., and Shelomova, L. F. (1994). Analysis of the mutagenic and teratogenic effect of griseofulvin in the mutagen-sensitive line mus(2)201 ${ }^{G 1}$ of Drosophila melanogaster. Genetika 6, 796-800.

Junger, M. A., Rintelen, F., Stocker, H., Wasserman, J. D., Vegh, M., Radimerski, T., et al. (2003). The Drosophila Forkhead transcription factor FOXO mediates the reduction in cell number associated with reduced insulin signaling. J. Biol. 2:20. doi: 10.1186/1475-4924-2-20

Kimura, K., Tanaka, N., Nakamura, N., Takano, S., and Ohkuma, S. (2006). Knock-down of mitochondrial heat shock protein 70 promotes progeria-like phenotypes in C. eleganset. J. Biol. Chem. 282, 5910-5918.

Kusama, S., Ueda, R., Suda, T., Nishihara, S., and Matsuura, E. T. (2006). Involvement of Drosophila Sir2-like genes in the regulation of life span. Genes Genet. Syst. 81, 341-348.

Lam, E. W.-F., Francis, R. E., and Petkovic, M. (2006). FOXO transcription factors: key regulators of cell fate. Biochem. Soc. Trans. 34, 722-726.

Landis, G. N., Abdueva, D., Skvortsov, D., Yang, J., Rabin, B. E., Carrick, J., et al. (2004). Similar gene expression patterns characterize aging and oxidative stress in Drosophila melanogaster. Proc. Natl. Acad. Sci. U.S.A. 101, 7663-7668.

Le Bourg, E. (2001). Oxidative stress, aging and longevity in Drosophila melanogaster. FEBS Lett. 498, 183-186.

Majercak, J. M. (2002). The effects of light and temperature on the Drosophila circadian clock. Diss. Abstr. Int. 1, 98.

Massie, H. R., Aiello, V. R., and Williams, T. R. (1993). Influence of photosensitizers and light on the life span of Drosophila. Mech. Ageing Dev. 68, 175-182.

Massie, H. R., and Whitney, S. J. (1991). Preliminary evidence for photochemical ageing in Drosophila. Mech. Ageing Dev. 58, 37-48.

Mattson, M. P., Duan, W., and Maswood, N. (2002). How does the brain control lifespan? Ageing Res. Rev. 1, 155-165.

Morrow, G., Samson, M., Michaud, S., and Tanguay, R. M. (2004). Overexpression of the small mitochondrial Hsp22 extends Drosophila life span and increases resistance to oxidative stress. FASEB J. 18, 598-599.

Moskalev, A. A., Krementsova, A. V., and Malysheva, O. A. (2008). Melatonin influence on Drosophila melanogaster life span at different light regimes. Ekol. Genet. 3, 22-30.

Moskalev, A. A., and Malysheva, O. A. (2009). Effect of illumination regime on life span in Drosophila melanogaster. Ekologiya 3, 221-226.

Moskalev, A. A., and Malysheva, O. A. (2010). The role of transcription factors DFOXO, DSIR2 and HSP70 in lifespan alteration of Drosophila 
melanogaster in different light conditions. Ekol. Genet. 3, 67-80.

Moskalev, A. A., Shostal', O. A., and Zainullin, V. G. (2006). Genetics aspects of different light regime influence on Drosophila life span. Adv. Gerontol. $18,55-58$.

Niedernhofer, L. J., and Robbins, P. D. (2008). Signaling mechanisms involved in the response to genotoxic stress and regulating lifespan. Biochem. Cell. Biol. 40, 176-180.

Orr, W. C., and Sohal, R. S. (1994). Extension of life-span by overexpresion of superoxide dismutase and catalase in Drosophila melanogaster. Science 263, 1128-1130.

Orr, W. C., and Sohal, R. S. (2003). Does overexpression of $\mathrm{Cu}, \mathrm{Zn}$-SOD extend life span in Drosophila melanogaster? Exp. Gerontol. 38, 227-230.

Phillips, J. P., Tainer, J. A., Getzoff, E. D., Boulianne, G. L., Kirby, K., and Hilliker, A. J. (1995). Subunitdestabilizing mutations in Drosophila copper/zinc superoxide dismutase: neuropathology and a model of dimer dysequilibrium. Proc. Natl. Acad. Sci. U.S.A. 92, 8574-8578.

Rogina, B., and Helfand, S. L. (2004). Sir2 mediates longevity in the fly through a pathway related to calorie restriction. Proc. Natl. Acad. Sci. U.S.A. 101, 15998-16003.

Russell, S. J., and Kahn, C. R. (2007). Endocrine regulation of ageing. Nat. Rev. Mol. Cell Biol. 8, 681-691.

Sheeba, V., Chandrashekaran, M. K., Joshi, A., and Sharma, V. K. (2002). Developmental plasticity of the locomotor activity rhythm of Drosophila melanogaster. J. Insect Physiol. 48, 25-32.

Sheeba, V., Sharma, V. K., Shubha, K., Chandrashekaran, M. K., and Joshi, A. (2000). The effect of different light regimes on adult life span in Drosophila melanogaster is partly mediated through reproductive output. J. Biol. Rhythms 5, 380-392.

Soti, C., and Csermely, P. (2007). Protein stress and stress proteins: implications in aging and disease. J. Biosci. 32, 511-515.

Staveley, B. E., Phillips, J. P., and Hilliker, A. J. (1990). Phenotypic consequences of copper-zinc superoxide dismutase overexpression in Drosophila melanogaster. Genome 33, 867-872.

Tanno, M., Sakamoto Jun., Miura, T., Shimamoto, K., and Horio, Y. (2007). Nucleocytoplasmic shuttling of the NAD-dependent histone deacetylase SIRT1. J. Biol. Chem. 282, 6823-6832.
Vinogradova, I. A., Anisimov, V. N., Bukalev, A. V., Semenchenko, A. V., and Zabezhinski, M. A. (2009). Circadian disruption induced by light-at-night accelerates aging and promotes tumorigenesis in rats. Aging 10 , 855-865.

Vogt, P. K., Jiang, H., and Aoki, M. (2005). Triple layer control: phosphorylation, acetylation and ubiquitination of FOXO proteins. Cell Cycle 4 908-913.

Received: 25 September 2012; accepted: 28 December 2012; published online: 25 January 2013.

Citation: Shostal OA and Moskalev AA (2013) The genetic mechanisms of the influence of the light regime on the lifespan of Drosophila melanogaster. Front. Gene. 3:325. doi: 10.3389/fgene.2012.00325

This article was submitted to Frontiers in Genetics of Aging, a specialty of Frontiers in Genetics.

Copyright (c) 2013 Shostal and Moskalev. This is an open-access article distributed under the terms of the Creative Commons Attribution License, which permits use, distribution and reproduction in other forums, provided the original authors and source are credited and subject to any copyright notices concerning any third-party graphics etc. 